\title{
Comparison Between ARIMA and VAR Model Regarding the Forecasting of the Price of Jute Goods in Bangladesh
}

\author{
Shahanaj Parvin ${ }^{1}$ and Murshida Khanam*2 \\ ${ }^{I}$ Department of Statistics, Jagannath University, Dhaka 1100, Bangladesh \\ ${ }^{2}$ Department of Statistics, Dhaka University, Dhaka 1000, Bangladesh
}

(Received: 24 September 2017 ; Accepted : 2 July 2018)

\begin{abstract}
In this study we used Autoregrressive Intigrated Moving Average (ARIMA) and Vector Autoregrressive (VAR) model to analyze and forecast the price of total Jute Goods with four of its types, where data has been collected from Bangladesh Jute Mills Corporation (BJMC) from the year 1980-81 to 2013-2014. In this study, a comparison has been made regarding ARIMA model and VAR model to investigate which model is the best to forecast. The methodology employed in this study is the co-integration and Granger Causality under VECM. The Augmented Dickey Fuller (ADF) Test has been performed to test the stationarity of the data set. The findings of this study suggested that in forecasting the price of jute goods of Bangladesh, the ARIMA model is more efficient than VAR model.
\end{abstract}

Keywords: ARIMA, VAR, VECM, ADF

\section{Introduction}

Jute is a natural fiber and it was called the "Golden Fiber" of Bangladesh. Nowadays, jute industry is in a vulnerable condition. But jute products could be great sources to earn so mach foreign currencies. On the other hand, jute is an environment friendly product. In the present study, an attempt has been performed to forecast the price of jute goods in Bangladesh. The major focus has been taken to carry out the models and then made a forecasting.

Economic forecasting is a fast-growing field. It has wide applicability in business and Government. The forecasting models used in Econometrics consists of systems of relationships between the variables of interest. These relationships are estimated from the available time series data. These models are used to forecast future events based on present and past information.

Day by day the popularity of the time series data has been increasing. The researchers are interested to perform research of time series data more than before. Forecasting plays a vital role in Econometrics research. Moreover, by using forecasting policy planners can perform their policy formulation in a sophisticated way. But now a question, why we did research on Forecasting the price of Jute Goods in Bangladesh using ARIMA and VAR model. We can answer this question in two ways. One point is that the forecasting the price of jute goods can make valid as well as legitimate economic policy for forthcoming years. On the other hand, we used ARIMA model and VAR models. These models are also popular in the Econometric arena. By using these models we conducted an exercise which would be a good example for academic research.

In recent years, more and more attention has been given to modeling and forecasting the non-linearity in various macroeconomic series, such as GDP, inflation and unemployment rate. A number of models have been applied, such as the Generalized Autroregressive Conditional Heteroscedastic model, Exponential Smoothing,

\footnotetext{
*Author for correspondesnce. e-mail: murshida@du.ac.bd
}

Autoregressive Integrated Moving Average (ARIMA), Vector Autoregression (VAR) and so on. Among them ARIMA model is more popular. The major benefit of Box-Jenkins ARIMA method is that it provides instantaneous and short term forecasting. According to the study of previous literature it can be said that it fits the data well. The researchers can be able to perform analysis to select a best model. On the other hand, the Vector Autoregression (VAR) modeling provides a new window for analyzing casually related endogenous variables, for example, sectors of Jute, VAR deals with time series macroeconomic data sets and forecast with consideration of casual relationship among the variables. VAR also account an econometric shock, which is impulse response of one variable to others.

In this paper, we used ARIMA and VAR model to analyze price of total jute goods with four of its sectors where data are extracted from Bangladesh jute Mills Corporation (BJMC) from the year 1980-81 to 2013-14. This study also makes a comparison of these two forecasting techniques to see which suits better in forecasting the price of total jute goods and its components.

There are so many research works have been conducted related with the present studies. Some of them have been focused as below:

Akhtaruzzaman ${ }^{1}$ used co-integration and vector autoregression (VAR) techniques to identify the determinants of income velocity of money (VM) in Bangladesh, covering both narrow and broad money in his paper. The study observed that financial development affects VM negatively. The VAR estimates showed that two variables, real GDP growth and financial development, jointly account for around half of the variance of speed of VM for both M1 and M2. The results showed that it was important for the monetary authorities to take into account both stages of economic and financial development in forecasting VM for designing effective monetary policy in Bangladesh. 
Rahman $^{2}$ h a s conducted a study to find out the best fitted model. After that the best fitted ARIMA model could be used for forecasting Boro rice production in Bangladesh from 2008-2009 to 2012-2013. From this study, it has been found that the ARIMA $(0,1,0)$ ARIMA $(0,1,3)$ and ARIMA $(0,1,2)$ are the best for local, modern and total Boro rice production respectively. It has also been found that the short term forecasting are more efficient for the ARIMA models.

In 2011 a study has been conducted to forecast the demand and price of wholesale vegetable marker considering Bangladesh. From this study, it has been found that the ARIMA model is authorized to use sales data of wholesale vegetable market ${ }^{3}$.

In 2013 Khanam and Hafsa ${ }^{4}$ studied on the forecasting behavior of watermelon production in Bangladesh by using Supply model, Log-linear model, ARIMA model and MARMA model. From this study, it has been found that the ARIMA model is the best model for forecasting purpose comparing with the MARMA model.

Hanif and Khanam ${ }^{5}$ used VAR model, ARIMA model and Holt's linear trend model to forecast the selected macroeconomic time series variables (GDP, FDI and Remittance). It has been found that the VAR model is the much more efficient model than others two.

\section{Objectives of the Study}

- To find suitable ARIMA models for price of the total jute goods and forecasting about future values. This study is also concerned about the forecasting accuracy of Box-Jenkins ARIMA models.

- To perform VAR model considering the price of some kinds of jute goods namely "Hessian", "Sacking", "Carpet Backing Cloth(C.B.C)", and "Others" and also making forecasting from VAR model.

- To find suitable ARIMA models for the prices of selected four types of jute goods ( "Hessian", "Sacking", "Carpet Backing Cloth(C.B.C)", and "Others") separately and making forecasting.

- And finally to compare the forecasting accuracy between the results obtained from the ARIMA model and VAR model.

\section{Data}

The present study considered the annual time series quantitative data for the period 1980-81 to 2013-14. The data has been collected from the Management Information System (MIS) reports of Bangladesh Jute Mills Corporation (BJMC).

\section{Variables of the study}

In this study, forecasting has been made for the price of total jute goods and the three main sectors and others. So the sectors under the study are: Hessian, Sacking, Carpet Backing Cloth (C.B.C.) and others. Hessian is used for bags, wrappers, wall-coverings, upholstery, and home furnishings. Sacking is a fabric which is made from the heavy jute fibers. C.B.C. is mainly used as a backing material of carpets and is of great demand in the carpet industry. In this study, others consists of yarn, apparel etc.

\section{Theoretical background}

In this study we used the Autoregressive Integrated Moving average (ARIMA) model and Vector Autoregression (VAR) model to forecast the price of the different types of jute goods. We considered the ARIMA (p, d, q) model where there are $\mathrm{p}$ autoregressive terms and $\mathrm{q}$ moving average term, and the series has to be differenced $d$ number of times in order to make it stationary. For further details of the ARIMA model Gujarati $(1980)^{6}$ is referred to. The model for ARIMA $(1,1,1)$ can be expressed as:

$w_{t}=\theta+\alpha_{1} W_{t-1}+\beta_{0} v_{t}+\beta_{1} v_{t-1}$

where $w_{t}$ is the first difference of the series of $Y_{t}$ (say).

The Vector Autoregression (VAR) model, on the other hand, is a random process model that is used to capture the linear interdependence among the several series. According to $\operatorname{Sims}(1980)^{8}$, VAR model generalizes the univariate autoregressive model by involving more than one variable. Each variable has an equation that explains its evolution with the help of its own lagged values, the lagged values of other variables included in the model and an error term ${ }^{7}$.

The measure of prediction accuracy of a forecasting technique in statistics is the mean absolute percentage error (MAPE).

$$
M A P E=\frac{1}{n} \sum_{i=1}^{n} \frac{\left|A_{i}-F_{i}\right|}{A_{i}} \times 100
$$

Where $A_{i}$ is the actual value and $F_{i}$ is the forecast value ${ }^{8}$.

\section{Results and Discussion}

In this paper the Augmented Dickey Fuller (ADF) Test was carried to test stationarity. For Hessian data stationarity was found after first difference at 5\% level of significance and for the remaining goods after second difference at $5 \%$ level of significance stationarity was found. Table 1 shows the overall results of stationarity.

Table 1. ADF test to check stationarity

\begin{tabular}{|c|c|c|c|c|}
\hline $\begin{array}{c}\text { Name of } \\
\text { the } \\
\text { products }\end{array}$ & $\begin{array}{c}\text { ADF test } \\
\text { statistic } \\
\text { value }\end{array}$ & P-value & Difference & Conclusion \\
\hline Hessian & -4.2414 & 0.01426 & First & Stationary \\
\hline Sacking & -7.4676 & 0.0100 & Second & Stationary \\
\hline C.B.C & -4.3641 & 0.01024 & Second & Stationary \\
\hline Others & -5.7898 & 0.0100 & Second & Stationary \\
\hline
\end{tabular}


After checking stationarity we find a appropriate ARIMA model for each of the products (price of the jute goods) which will be used for forecasting the price of jute goods. Then finds Mean Absolute Percentage Error (MAPE) for both the ARIMA and VAR model. According to MAPE we decide which model is better for forecasting the price of jute goods. Table 2 shows the MAPE for each model and Table 3 shows the results of finding appropriate model for forecasting each of the products.

Table 2. Comparison between ARIMA and VAR model through the values of MAPE.

\begin{tabular}{|c|c|c|}
\hline Types of jute goods & $\begin{array}{c}\text { MAPE of } \\
\text { ARIMA }\end{array}$ & MAPE of VAR \\
\hline Hessian & $9.278 \%$ & $15.8892 \%$ \\
\hline Sacking & $18.899 \%$ & $30.4624 \%$ \\
\hline C.B.C & $27.793 \%$ & $14.263 \%$ \\
\hline Others & $20.898 \%$ & $49.698 \%$ \\
\hline
\end{tabular}

Table 3 shows the appropriate ARIMA model for each of the jute goods( Hessian, Sacking, C.B.C and Others) on the basis of AIC value.

Table 3. AIC values of the approprioate ARIMA model and VAR model of the price of the different types of jute goods.

\begin{tabular}{|c|c|c|}
\hline Types of jute goods & AIC & Appropriate model \\
\hline Hessian & 2.670 & ARIMA $(0,1,2)$ \\
\hline Sacking & 36.99 & ARIMA $(3,2,2)$ \\
\hline C.B.C & 26.74 & VAR $(4)$ \\
\hline Others & 53.81 & ARIMA $(0,2,3)$ \\
\hline
\end{tabular}

Forecasting of Hessian, Sacking, C.B.C and others using appropriate model graphically:

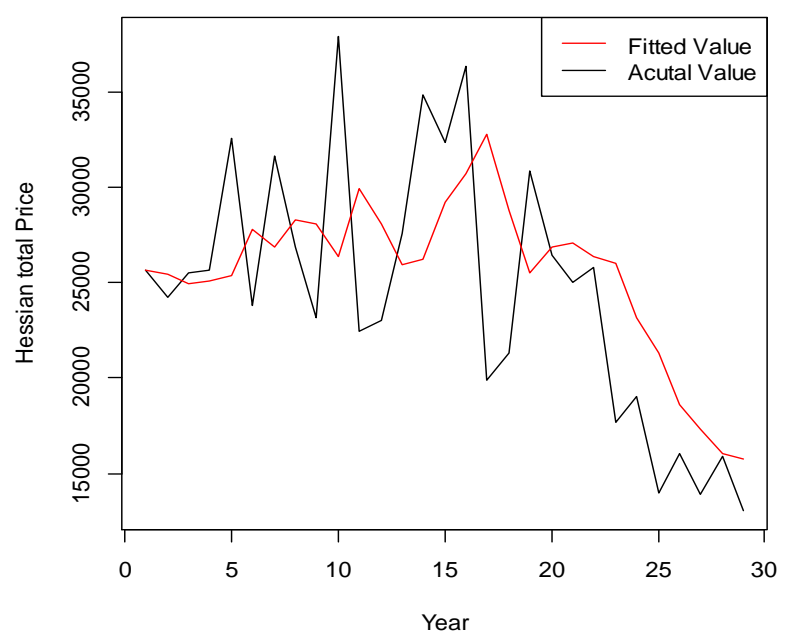

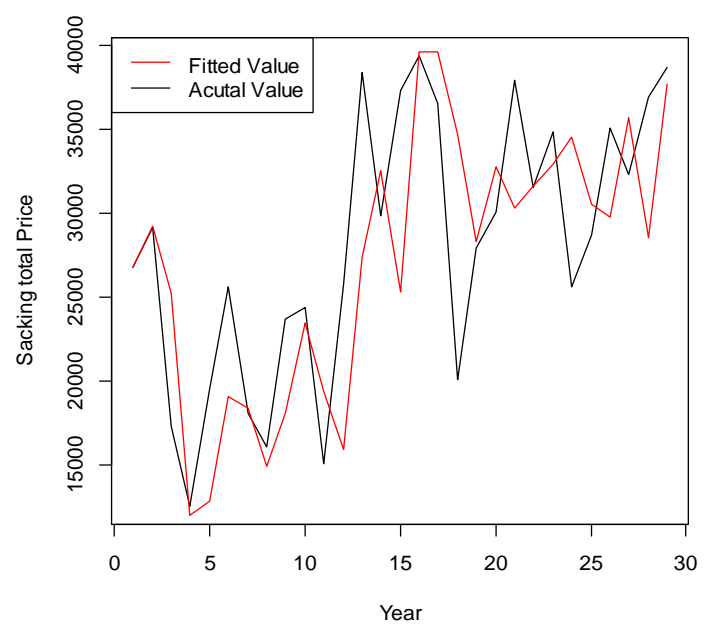
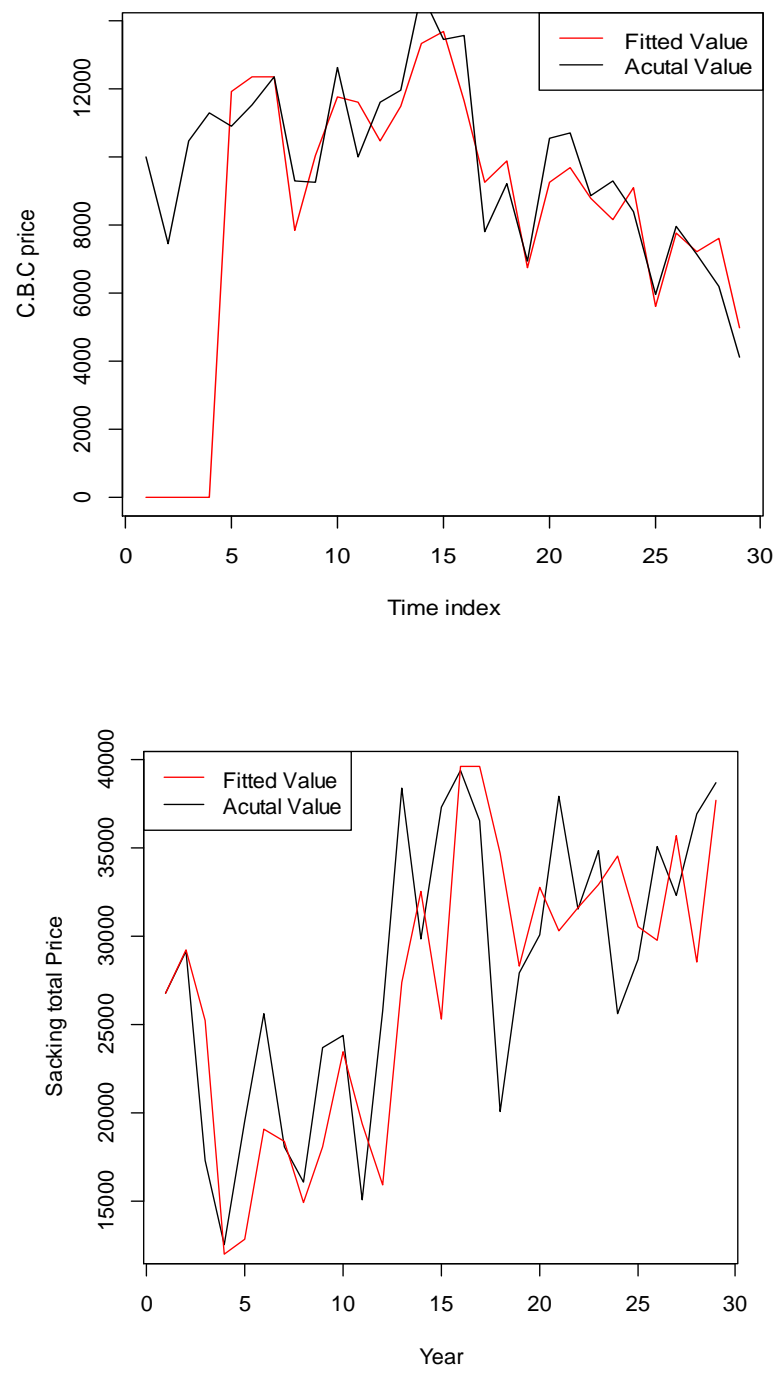

Above figure shows the actual and fitted values of Hessian, Sacking, C.B.C and Others using corresponding appropriate model graphically. 
Major findings of this study can be summarized as follows:

- It has been found that for forecasting the price of total jute goods, Box-Jenkins ARIMA model fits well as only $8.2176 \%$ MAPE has been observed.

- The price of the four types of Jute Goods (Hessian, Sacking, C.B.C and Others) have been forecasted by using the VAR model and the ARIMA model. In comparison of forecasting accuracy we have found that ARIMA model is more efficient than VAR for the selected three types of Jute Goods and for only one types of products VAR model is better suited than ARIMA model.

\section{For Hessian}

In forecasting the price of Hessian, it has been found that in ARIMA model the Mean Absolute Percentage Error (MAPE) is $9.278 \%$ and in VAR model the MAPE is $15.8892 \%$. So, we can conclude that ARIMA model is more efficient than VAR model.

\section{For Sacking}

In forecasting the price of Sacking, it has been found that in ARIMA model the Mean Absolute Percentage Error (MAPE) is $18.899 \%$ and in VAR model the MAPE is $30.4624 \%$. So, we can conclude that ARIMA model performs better than VAR model for the types of Sacking.

\section{For Carpet Backing Cloth (C.B.C)}

In forecasting the price of Carpet Backing Cloth (C.B.C), it has been found that in ARIMA model the Mean Absolute Percentage Error (MAPE) is $27.793 \%$ and in VAR model the MAPE is $14.263 \%$. So, we can conclude that VAR model is more efficient than ARIMA model.

\section{For Others}

In forecasting the price of Others, it has been found that in ARIMA model the Mean Absolute Percentage Error (MAPE) is $20.898 \%$ and in VAR model the MAPE is $49.698 \%$. So, we can conclude that ARIMA model is more efficient than VAR model.

So, at the final point on the basis of this study it can be said that as a whole ARIMA model is more appropriate than VAR model considering the forecasting of the price of the Jute Goods.

From analysis of ARIMA model it has been found that for the next six years say, 2015, 2016, 2017, 2018, 2019, 2020 the predicted value of price (TK in Lakh) for Hessian, Sacking, C.B.C and Others are given below in table 4:

Table 4. Predicted value (Price TK in Lakh) of year 2014-2015 to 2019-2020.

\begin{tabular}{|c|c|c|c|c|}
\hline Year & Hessian & Sacking & C.B.C & Others \\
\hline $2014-2015$ & 14701.75 & 39553.07 & 2562.457 & 891.9896 \\
\hline $2015-2016$ & 14701.75 & 40565.62 & 2694.136 & 875.7946 \\
\hline $2016-2017$ & 14701.75 & 41002.33 & 2331.085 & 859.5996 \\
\hline $2017-2018$ & 14701.75 & 41372.26 & 2303.247 & 843.4046 \\
\hline $2018-2019$ & 14701.75 & 41741.11 & 2032.978 & 827.2096 \\
\hline $2019-2020$ & 14701.75 & 42414.98 & 2024.802 & 811.0146 \\
\hline
\end{tabular}

\section{Conclusion}

- It can be said that ARIMA $(0,1,2)$ model is the best model for forecasting Hessian sales price.

- $\quad$ ARIMA $(3,2,2)$ model is the best model for forecasting Sacking sales price.

- VAR (4) model is the best model for forecasting the price of Carpet Backing Cloth (C.B.C).

- $\quad$ ARIMA $(0,2,3)$ model is the best model for forecasting Others sales price.

Finally, it can be said that ARIMA model is the best model for forecasting the price of Jute Goods comparing with VAR model on the basis of Mean Absolute Percentage Error (MAPE).The present study is an academic exercise for forecasting related issues. The findings of the present study can play a major role for further research as well as policy formulation to a great extent. Further research can be conducted in future by using the deliberation of the present study.

\section{References}

1. Akhtaruzzaman, M. 2009. Financial Development and Velocity of Money in Bangladesh: A Vector AutoRegression Analysis, Bangladesh Bank, Working Paper Series: WP 0806.

2. Rahman, N.M.F. 2010. Forecasting of Boro Rice Production in Bangladesh- An ARIMA approach. J. Bangladesh Agril. Univ., 8(1); 103-112. retrieved October 162012 from http://www.banglajol.info/index.php/JBAU/article/download/ $6406 / 4901$

3. Shukla,M. and Jharkharia, S.2011. Applicability of ARIMA Models in Wholesale Vegetable Market. An Investigation. Proceedings of the 2011 International Conference on Industrial Engineering and Operations Management. Retrieved October 16 2012 from http://www.iieom.org/ieom2011/pdfs/IEOM172.pdf http://en.wikipedia.org/wiki/Jutes

4. Khanam, and Hafsa, 2013. Market Model Analysis and Forecasting Behavior of Watermelon Production in Bangladesh, Bangladesh Journal of Scientific Research., 26(1\&2), 47-56.

5. Hanif, and Khanam, 2017. Analyzing the impact of Remittance and FDI on GNP in Bangladesh: An Econometric Time Series Analysis, South Asian Journal of Population and Health, 10(1\&2), 97-107.

6. Gujarati, N.2008. Basic Econometrics, Fourth edition, Tata McGraw Hill Publishing Company Limited, New Delhi.

7. Sims, C.A. 1980. Macroeconomics and Reality, Econometrica, 48, $1-48$.

8. Wikipedia. Org. 